\title{
Salutogenic Architecture in Healthcare Settings
}

\author{
Jan A. Golembiewski
}

\section{Introduction}

In recent years, the term 'salutogenic' has become a buzzword for marketing architecture for health and nursing care. The term was coined to describe a model for socioenvironmental influences on health, but in the designers' hyperbole it now rarely means more than fuzzy intentions to create restorative environments by providing views that represent nature: whether it be designed parkland, grassy areas, views of the sky or even video representations of these things. The term is thus bleached of meaning. The design industry needs a theory to establish whether or not views of nature are likely to be restorative on a case-by-case basis, and perhaps more importantly, to reach beyond this axiom and locate other ways to design and improve restorative environments. The marketer's sense that salutogenic theory is a powerful tool for understanding the impacts of the design process on the health and illness continuum is well-placed; as Antonovsky suggested, salutogenesis could be the only comprehensive theory of health promotion (1996), something the industry needs for the design process itself, not just for marketing spin.

Substantial evidence shows aesthetic design changes in healthcare settings can improve health outcomes for patients. A number of theories have been offered to explain these effects-but most of them are limited to the specific stimulus under the microscope of the theorists. Examples include an evolutionary hypothesis to explain the influence of 'views of nature' (Ulrich 1991), and the ecological theory of Lawton and Nahemow (1973), which argued that there is a 'sweet-spot' to be found in a trade-off between designing for comfort and designing for mental and physical challenges. Others argue that the most important issues for health in design are cleanliness and pathogen control

J.A. Golembiewski, BfA BArch MArch PhD ( $₫)$

Psychological Design, 1 Glenview St, Sydney, NSW 2021, Australia

e-mail: jan.golembiewski@qut.edu.au
(Dancer 2004). Lighting, soundscape design and things like wall paint colour have also been considered (Hurst 1960; Vaaler, Morken, \& Linaker 2005), along with seating layout in psychiatric settings (Bitterman 2013; Sloan Devlin 1992).

While these theories are all important to hospital design, they ignore the elephant in the room-that architecture can be psychologically manipulative, for better or for worse. Architecture does this by providing a narrative context that affects a person's behaviour, neural and endocrine systems, and through its influence on the brain and the body, architecture can directly influence health (Golembiewski 2016). Antonovsky's salutogenic theory provides an accessible overarching logic for determining these effects in design (Golembiewski 2012b).

Salutogenic theory is not a perfect model of health (Mittelmark \& Bull 2013), but as theory, it does have a scope and perspective that other ways of understanding health lack (Antonovsky 1996). Salutogenesis is a way of understanding the entire spectrum of wellness and illness, regardless of specificity and detail. In other words, it provides an overarching narrative structure that transcends the individual differences between people, and the differentiation between diagnoses, circumstances, environmental variation and so forth. Salutogenic theory is thus useful for 'broad-stroke' approaches to grappling the well-being and health/illness spectra, and as such, it is useful for managing indirect, complex, obscure or unknown factors in health conditions (this complexity typifies the health influences of the physical environment). Because Salutogenic theory has this higher-level validity that makes sense beyond the specific findings of particular experiments and design interventions (Strümpfer et al. 1998a; 1998b), it provides a basis for informed decision making in the absence of specific knowledge, or whenever circumstances are too complex to suggest easy solutions. Understanding this, Dilani (2006, 2008) and the International Academy of Design and Health (which he chairs) has actively promoted the theory to industry. The results have been a rapid improvement in the overall 
quality of new healthcare buildings around the world, and while this is very welcome, industry lacks the nuanced understanding of the theory needed to bespoke and expand the scope of salutogenic interventions.

Following from the above, this chapter discusses how salutogenesis can be, and has been, applied to healthcare architecture.

\section{The sense of Coherence}

Salutogenesis proposes that good emotional, psychiatric and somatic health is maintained through a dynamic ability to adapt to life's changing circumstances. The opposite is also true-forces that prevent the ability to adapt exert an aetiological influence on illness. One 'succumbs to illness', when demands exceed one's capacity to cope with them. So a germ on its own is insufficient to cause a disease-it needs to be cultured in an environment that has deficient capacity for resistance (Antonovsky 1972). Models that accept 'multiple causation' typically describe the forces that cause maladaptivity as 'stressors', a grab bag of influences that includes everything from joyous events to life's tragedies and banal concerns (Antonovsky 1987). In effect, everything can be considered a stressor, making stress a useless concept. The forces at work to improve adaptability, on the other hand, are specific enough to allow practical, buildable and highly bespoke solutions. These forces have been labelled a 'sense of coherence', also known as SOC (Antonovsky 1979).

The sense of coherence is the sum of all generalised resistance resources (or GRRs-hereafter 'resources') minus all generalised resistance deficits (Antonovsky 1987). Resources fall into three basic (but interrelated) domains-those that enhance comprehensibility, those that enhance manageability, and those that enhance meaningfulness. Resistance deficits (GRDs), on the other hand, are the ubiquitous challenges to these resources. Resistance deficits are entropic, meaning that without a positive sense of coherence thrust, resistance deficits exert a continuous disintegrative force, allowing illness to overcome a person (Antonovsky 1996). With the total failure of manageability, death ensues, unless the most basic support for manageability is delegated to intensive care systems.

When one is unable to adapt to circumstances and experiences, physical or mental health will 'breakdown' (Antonovsky 1972, p. 64). But by focusing on the sense of coherence and on resources, a scaffold emerges that can be readily applied to health facility design. Sense of coherencesupportive design can help liberate the resources that enable resistance to illness and reduce the disintegrative forces that cause maladaptation in the first instance.

\section{The Generalised Resistance Resources}

'Comprehensibility' is a person's ability to make sense of one's life narrative, one's context and current circumstances, and without this fundamental knowledge, people have little capacity to make the most of circumstances or negotiate life's challenges (Golembiewski 2012b). After all basic needs (manageability) are met, the desire to understand circumstances in order to make the most of them is essential. This is the essence of comprehensibility.

'Manageability' is a person's ability to manage day-today physical realities, like paying bills, staying warm, dry, clean, rested and nourished and other maintenance of their physical lives. At a minimum, it serves the basic requirements to maintain homeostasis: to maintain body temperature, blood glucose, hydration and other critical somatic concerns (Golembiewski 2012b).

'Meaningfulness', according to Antonovsky (1979) and Frankl (1963), is the foundation of the desire to live. It is meaningfulness that gives life forward thrust- the will to resist the entropy of illness and death's inevitability, and as such it is possibly the most important of the salutogenic resources. Meaningfulness is also the most elusive because meaning is difficult to define and is highly personal. Meaningfulness is found in the intensity of personal connections, responsibilities and desires with the outside world: 'Profound ties to concrete, immediate others ... and between an individual and his community are decisive resistance resources' (Antonovsky 1972, p. 542). People find meaning in different social groupings, in different causes and concerns, and often disagree wholeheartedly about how concerns should be prioritised. Yet, it is in these distinctions that people find the basis of a sense of identity (Frankl 1963; Searles 1966). Without meaningfulness, people find themselves utterly bereft of meaning and of any desire to act (Searles 1960, 1966).

\section{The Biochemical Response to Design}

Both animals and people behave radically differently when threatened and when they are happy (Calhoun 1970; Isovich, Engelmann, Landgraf, \& Fuchs 2001; Salmivalli 2001). They behave more accommodatingly when they are elated with lofty emotions such as awe. These emotions are not superficial but have real and long-lasting implications (Rudd, Vohs, \& Aaker 2012). The science is relatively new, and requires far more research, but it appears that a number (if not all) of the neurotransmitters react to environmental stimuli, and therefore react to design (Golembiewski 2016). Acetylcholine, for instance, moderates balance, homeostasis, muscular tone and most of the things we 
associate with comfort-body warmth, the senses of touch and hunger (Changeux \& Edelstein 2005). Light is thought to moderate serotonin and the hormones on the serotonergic pathway such as melatonin (Rao et al. 1992). In turn, these hormones have an influence on circadian rhythms, control of inflammation and among other things, the mobility of gallstones. The other neurotransmitter that can be highly reactive to environmental stimuli is dopamine (Koppisetti et al. 2008), and this neurotransmitter is the one that's most closely associated with the emotions.

Dopamine is interesting because it is directly implicated in many mental illnesses (Howes et al. 2013). Dopamine has strong connections in the limbic area of the brain (Floresco, Blaha, Yang, \& Phillips 2001), an area characterised as the centre of both narrative cognition and emotional balance. The hypothesis is that dopamine mediates the intensity of our experience of stories. These stories are composed from information that is gathered from the environment around us by the hippocampi (which moderate story structure) and the amygdalae (which moderate ipseity: the sense that a story is about me) (Le Hunte \& Golembiewski 2014). Unfortunately, when people are mentally ill, and their dopamine is deregulated, they may suffer too much intensity for trifles, and too little in the face of important events.

The hypothalamus, another limbic organ, works like a switch: when the other organs signal that the emergent story indicates danger, the hypothalamus switches all the timeconsuming, thought intensive, creative and considered parts of the brain off, and instead switches the automatic and instinctive systems on. The hypothalamus also triggers the endocrine system to go into a kind of emergency mode, short-circuiting the normal endocrine cascade. Cholesterol is blocked from being reprocessed into oestrogen, progesterone, testosterone and other desirable and essential hormones as it normally would. Instead, cholesterol remains in its raw forms, ready to clog the vascular system (as this is a useful first line defence against bleeding or heart failure). Along with this, arginine vasopressin, corticotropin, cortisol and other hormones that are important in physical emergencies are released. These hormones dictate much of how we feel on an emotional level, but they more than just that: they protect the body from famine, dehydration and blood-loss, for example. However, just as we do not always need to feel panicked or angry, most of the negative responses these hormones trigger are redundant when the environment is physically safe or when health-building is an objective. After long-term exposure, all of the negative hormonal responses we see here are directly associated with the epidemiology of 'lifestyle disease'. On the other hand, stories that 'look good for me' - especially if the associated experiences are awe-inspiring, enable the rostral dopaminergic pathway to open, and with it a whole set of desirable behaviours and endocrinal effects, which feel good and aid recovery (Golembiewski 2012b, 2014a).

\section{Aesthetics, the Built Environment and Health}

For millennia humans have customised their accommodation as a resource to protect against danger, discomfort, wildlife, social threats and the deleterious effects of weather. Architecture's role in these protective purposes is fundamental. However, the supportive effect of architecture is not only physical, but psychological too-if people cannot find respite from the pressures of life at home, the resulting compounding mental and emotional strain may be enough to cause debilitating mental illness, possibly even without an underlying biological or genetic dysfunction (Golembiewski 2013). But all shelter is not equal: even once we have achieved the basic need for shelter from the weather, the wild and other humans, we continue to customise the environment on an aesthetic level, in what appears to be an attempt to make the environment better on a psychological level. And the evidence is that such efforts are rewarded.

The idea that aesthetics have any impact on health (and even on mortality) appears to be superstitious and occult and is thus not nearly as widely accepted as it should be (Golembiewski 2016). The concept of aesthetic impact on health has been scientifically tested thousands of times, including dozens of studies against a null hypothesis-a statistical method used to demonstrate causality. In 2005, a systematic review located and analysed 30 peer-reviewed articles that showed this effect to be significant and reliable (Dijkstra, Pieterse, \& Pruyn 2006), with findings that sometimes defy belief-for example, $30.8 \%$ faster recovery and $38 \%$ lower mortality were found when patients were given sunlit rooms for psychiatric disorders (Beauchemin \& Hays 1996, 1998).

From a salutogenic perspective, such findings are of immense importance: when people are healthy they demonstrate a theoretical surplus of resistance resources, so aesthetic improvements are redundant, but when people are ill, they suffer in the balance between deterioration and recovery, so any genuine influences (whether for better or worse) should reflect in outcomes.

There are a number of relationships that our bodies have with the outside world. Firstly, there's the physical relationship: the built environment is replete with restrictions-like fences and walls, and opportunities like pathways, bridges or windows and these determine many of the choices we make. Some of these are insignificant-for example, there is little phenomenological difference between a left or right turn, even though they are opposites. But many physical restrictions and opportunities moderate our behaviour, and are intended to do so. As such, they are an important target for policy design initiatives that aim to create healthy environments - for example, cities around the world are compiling 'fit city' design guidelines to encourage people to take the stairs, and leave the car behind, and walk or cycle 
instead (City of New York 2013; Jackson \& Sinclair 2012). Physical interventions like these are often thought to be the most the built environment can do to improve health.

But when people are recovering in a hospital, 'fit city' initiatives are of little use. Indeed, the one place where lifts and nearby parking is really useful is in a hospital, because when people are sick, it is not the time to impose an exercise regime. In the impressive results reviewed by Dijkstra et al. (2006), none of the health improvements of persons in healthcare institutions were because the hospitals had more steps or longer corridors. The causal factors were aesthetic - they were psychological rather than physical.

As pointed out early in this chapter, the traditional lens for understanding the impact of the built environment on health is focused on how well it provides basic functionality and shelter. This is especially true in healthcare, with its top requirement being that the built environment support more efficient patient management, more reliable clinical procedures, better infection control, etc. The main point of this chapter is to demonstrate that this is a very low bar. Salutogenic architecture has the capability to also support enhanced patient manageability, comprehensibility and meaningfulness, and their collective synthesis: the sense of coherence, in other words to help a person through the natural process of recovery.

\section{Architecture and Patient Manageability}

The traditional healthcare environment addresses pretty much only manageability, one of the three GRRs. So, if there is any context that is well understood in the healthcare setting, it is planning for manageability. Hospitals make environments more manageable for staff via centralised food and cleaning services and more manageable for patients through intravenous drips, incubation, heating, cooling, catheterisation, dialysis, ventilation and cardiopulmonary bypasses, etc. In a hospital, it is striking just how much a patient's life can be maintained by others-indeed, patients do not even need to breathe for themselves. It is hardly a stretch to say manageability is traditionally the only organising principle when designing healthcare facilities: thus better patient oversight, better infection control, more efficient catering, laundry, pharmacy, filing and even parking are prioritised over whimsical things like aesthetics.

At its most basic, the architect's role in improving manageability in the healthcare milieu involves improving the delivery of all the services that the hospital already considers. In hospital briefing jargon, this is 'the functionality' of the unit. But an architect armed with an understanding of salutogenesis can go much further; paying attention to how design can enhance the patient's resources for recovery
(Golembiewski 2010). Nowhere is this more important than in psychiatric facilities-especially for long stays. These facilities are routinely designed with centralised staff stations, both to improve manageability for the staff, and also to completely disempower patients, whose actions are considered bad, irritating for staff and even dangerous (Foucault 1977). To prevent this loss of independence and the subsequent atrophy of essential life skills, MAAP (an international architectural firm with a reputation for healthcare design innovation, where the author worked until mid-2016) routinely does away with central staff stations, thereby turning the locus of control from the staff back to the patients. To enable alternative opportunities for patient-monitoring that are discrete and democratic, we identify informal places where nurses can sit and observe most of the goings on in the unit (Golembiewski 2014a) (Fig. 26.1).

\section{Architecture for Patient Comprehensibility}

In contrast to the traditional approach to health facility architecture, salutogenic design aims to enhance not only just manageability for the institution, but also the manageability, comprehensibility and meaningfulness of the patient.

Comprehensibility is the capacity to understand and negotiate the contexts we find ourselves in. As Donne observed in 1624, hospitals have a long tradition as places where such understanding is delegated. In a hospital, a patient is rarely expected to understand what they are suffering from or how the service is going to make them better. When a patient enters a hospital, a receptionist or triage nurse will tell them where to go and it is the doctor's responsibility to know what was wrong with them and how to treat their affliction. But this is changing. Patients now have tools at their disposal for self-diagnosis and treatment, and this awareness has become essential for the basic maintenance of good health and for identifying illnesses early (Parker 2000).

After an era of neglect, architecture has now begun to provide for patient comprehensibility in a meaningful way. For example, as the carefully crafted patient journeys in the Centre for Respite and Recovery (Fig. 26.2) illustrates, the centre is truly designed so patients can rest assured that there could be no better place to recover, and this knowledge does assist recovery (Golembiewski 2016). A much greater emphasis on intuitive way finding is now de rigeur, and this, in a more minor way helps patients to help themselves. Architecture now looks to outdoor views for global orientation, identifiable urban street patterns and the use of distinctive landmarks like sculptures. But comprehensibility in a salutogenic sense is far more than just 
Fig. 26.1 Psychiatric centres designed without centralised staff stations turn the locus of control from staff back to the patients. In these facilities, everyone has good observation, not only the staff. This is an essential response to recovery centred models of care. Image courtesy of the Author and MAAP

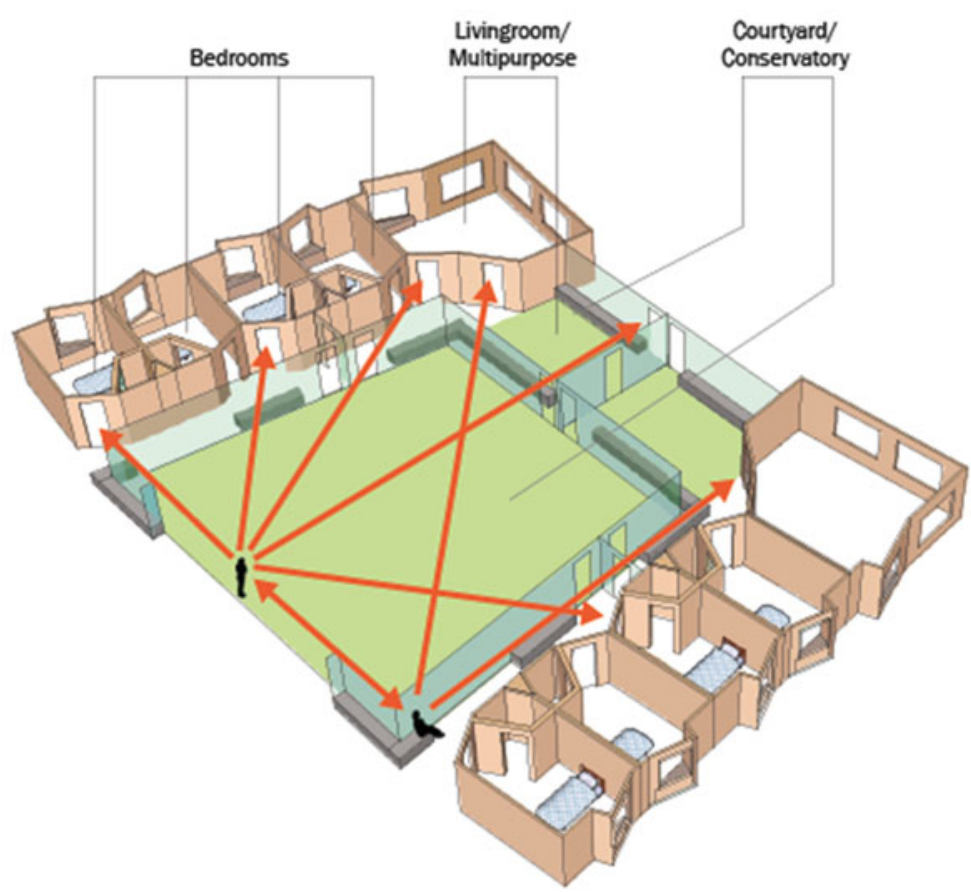

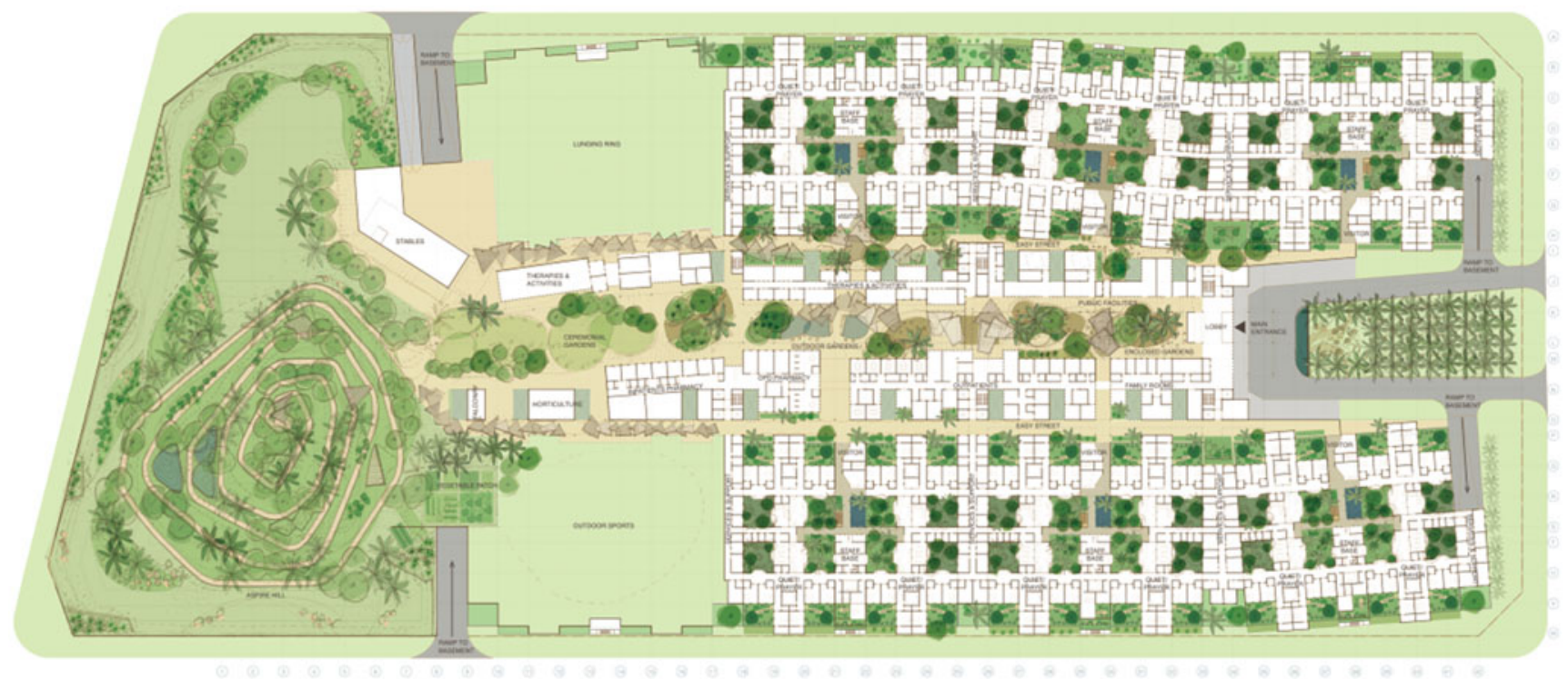

Fig. 26.2 The plan of The Centre for Respite and Recovery (MAAP, Aecom and Makower Architects) has an urban street-grid like plan to enable intuitive way-finding, it is littered with gardens, has horse stables and a lunging arena to train them and an aviary also, where

knowing where to go or knowing about medical conditions. More importantly, comprehensibility is used to enhance or reinforce a person's efficacy in their endeavours. In this centre, patients are given the opportunity to train horses and birds in order to develop skills and demonstrate evidence personal success. patients can keep and train birds. These affordances are all designed to maximise opportunities for self-empowerment and to generate the feeling there is a high probability that things will work out for the best. Image courtesy of MAAP and the Author

The question then is, how does healthcare architecture enhance our sense of personal narrative - the sense we make of the context we find ourselves in? Even the most fundamental axioms of understanding (and therefore of comprehensibility) are structured in narrative terms: a premise, a process and a conclusion. The most important aspects of 
comprehensibility in healthcare settings revolve around the narratives of a patient's sequential experience while negotiating 'the patient journey' (or as it was called in the beaux arts tradition, the marche).

The narrative sequence has the capacity to foster a sense of control and personal security, but without sufficient care, our natural inclination to perceive narratives and read the environment can also destroy confidence. A patient can all too easily discover themselves on a set from a medical drama: on a bed, surrounded by blue vinyl curtains, next to a machine with a red flashing light. In the medical drama, the setup spells inevitable disaster, and so the architectural vocabulary takes the same hue. Shiny vinyl floors, windowless rooms, machines with flashing lights, blue curtains and strip lighting are all therefore to be avoided.

Instead, the Centre for Respite and Recovery is a psychiatric facility design that would be rejected by TV set-finders (Fig. 26.2). All bedrooms are private, they have king-sized beds, they open out onto leafy gardens, the lights are dimmable, the windows and doors are usable, there are timber and stone finishes and high coffered ceilings and the colours and textures are rich and non-institutional. The language used extends to the typology of the building: it reads as a resort or a fancy hotel-a place where the promise of respite and recovery rings true. This building was purposefully designed to give patients the 'dynamic feeling of confidence that one's internal and external environments are predictable and that there is a high probability that things will work out as well as can reasonably be expected' (Antonovsky 1987, p. xiii). As we see from the Centre for Respite and Recovery, it is well within the designer's capacity to use salutogenic principles in order to help a patient feel secure (Fig. 26.3).

\section{Architecture for Patient Meaningfulness}

"... how little and how impotent a piece of the world is any man alone?" (Donne 1624)

Because meaning in life is so important for one's sense of coherence, it should be a pivotal concern for architects when designing for better healthcare. But meaningfulness has an intrinsic relationship with the real-world outside the facility: people's most significant thoughts are likely to be for animals, the global ecology, for religion, politics, sport, for family, friends, for music, art, literature, perhaps the exercise of power. Hospitals are not ideal places to affirm meaning, because patients are physically removed from most of that which gives life meaning: they are full of Kafakaesque endless corridors, broken promises ('you'll feel better soon; you might feel a little uncomfortable ...'), false alarms, of institutional aesthetics and inconsistent care (Wistow 2012). Hospitals also create social isolation by restricting the visiting hours of friends and family and by forbidding pets.

Yet, the healthcare architect can still design to enhance meaningfulness for patients. People very rarely actively search for meaning, but the right context might inspire a search, or at least enrich one. Khoo Teck Puat Hospital in Singapore provides an abundance of planting, thereby encouraging an explosion in wildlife in the public areasthey even have a butterfly register (Fig. 26.4)! This is intended to inspire patients with the wonders of the world. The Royal Children's Hospital has a meercat enclosure for similar reasons (Fig. 26.5). At the Centre for Respite and Recovery, patients tend horses and birds; there are also really good facilities for visitors (especially for visiting children), so patients can be expected to receive happier and more regular visitors, thereby promoting a sense of belonging (Smith, Golembiewski, Hunyh, Raz, \& Wu 2014). In Wilcannia Hospital, which caters for especially for an indigenous population in Australia, architect Dillon Kombumerri designed patient accommodation on the ground floor, with wide verandas looking out into native landscapes to allow space for visits from the tribe (typically people arrive in large numbers rather than individually) and to let patients know that their tribal mores are respected and acknowledged (Fig. 26.6).

\section{Discussion}

Since Dilani (2006) brought the concept of salutogenesis to healthcare design, he has led the International Academy for Design and Health to promote salutogenic theory in healthcare architecture throughout the world, even offering an annual prize for excellence in salutogenic architecture. As a result, the concept has grown in popularity and has become a buzzword in the healthcare architecture procurement chain. The result is that salutogenesis is now a respected and encouraged design goal. The downside is that the term 'salutogenic' is overused by architects, most of whom do not know how to drive their schemes with a salutogenic methodology, and do not even have a solid grasp of what salutogenesis means. As a result, at times, the term can mean nothing more systematic than 'friendly-looking' or 'leafy'. This is not to criticise those designs-after all, 'nice looking' and 'leafy' are often the outcomes of more systematic salutogenic approaches, but there is so much more unexplored potential in the concept. There are now systematic methods to bring salutogenic principles into healthcare design (Golembiewski 2010) and emergency care (Golembiewski 2012a). And when adopted 
Fig. 26.3 Sculptures and bright colours to provide a sense of play and to serve as landmarks for orientation in Lady Cilento Children's Hospital. The architects (Conrad Gargett \& Lyons Architects) hope these innovations will improve the salutogenic sense of comprehensibility. Image by Christopher Fredrick Jones, courtesy of Conrad Gargett and Lyons

Fig. 26.4 The patient spaces at Khoo Teck Puat Hospital (CPG Consultants, architects and Peridian Asia and landscape architects) are environments for butterflies and other wildlife, in the hope that the abundance of nature will inspire patients and therefore enrich meaningfulness. Image courtesy of CPG Consultants
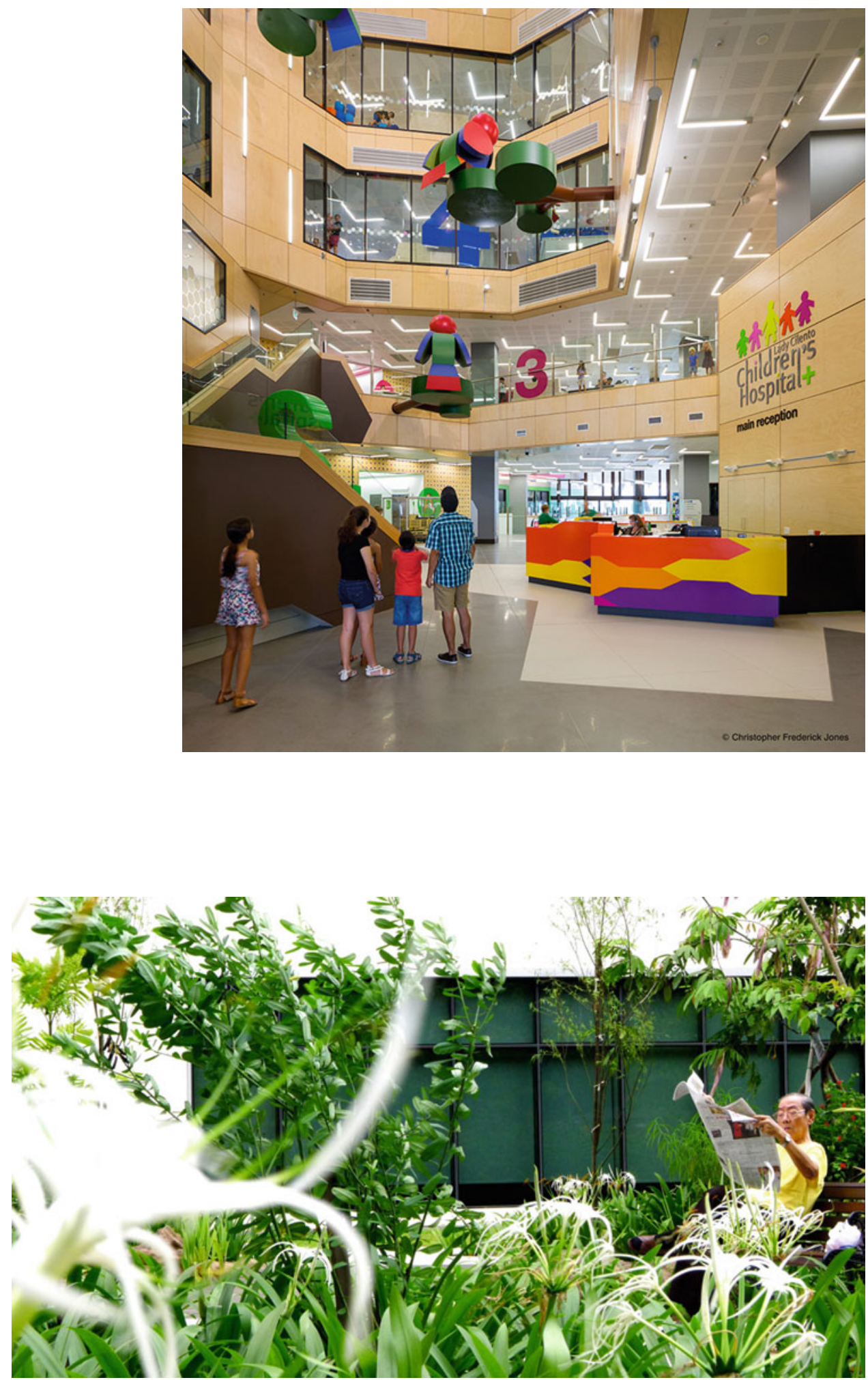
Fig. 26.5 The ambulant area in the Royal Children's Hospital (Bates Smart, Billard Leece and HKS) has a habitat for meercats to develop a sense of meaningfulness by keeping children engaged in enquiry about the world around them. (Photo by John Gollings, courtesy of Bates Smart)

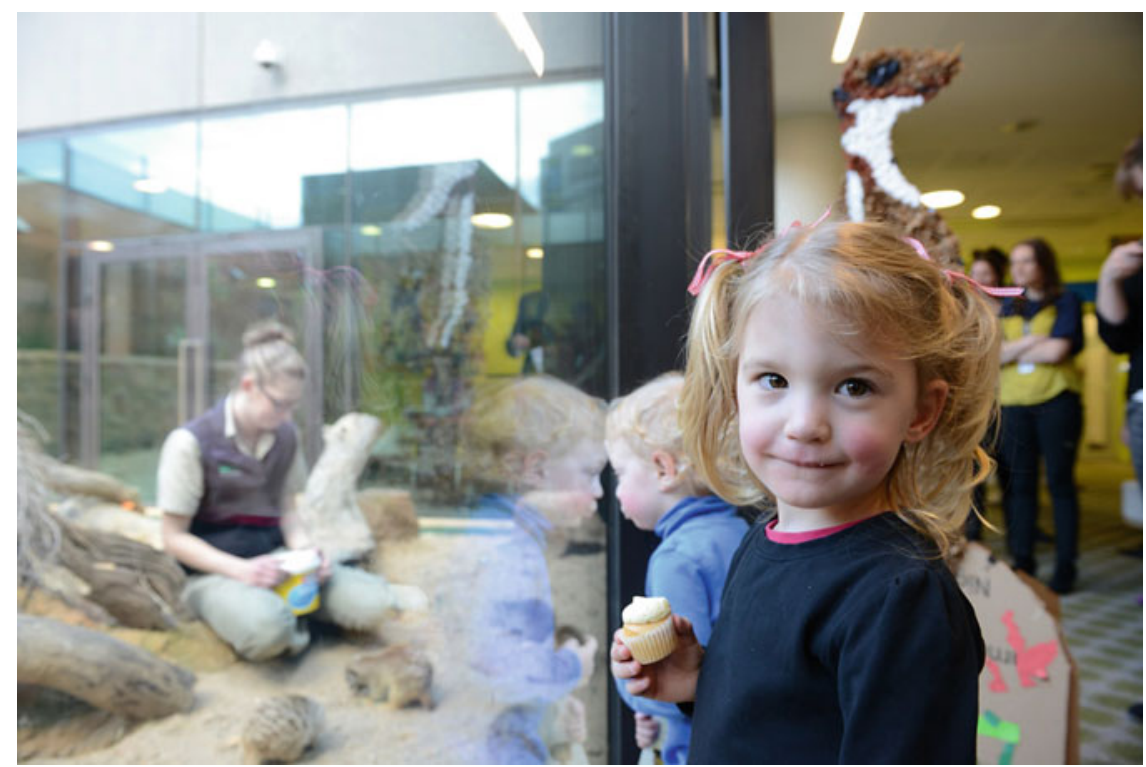

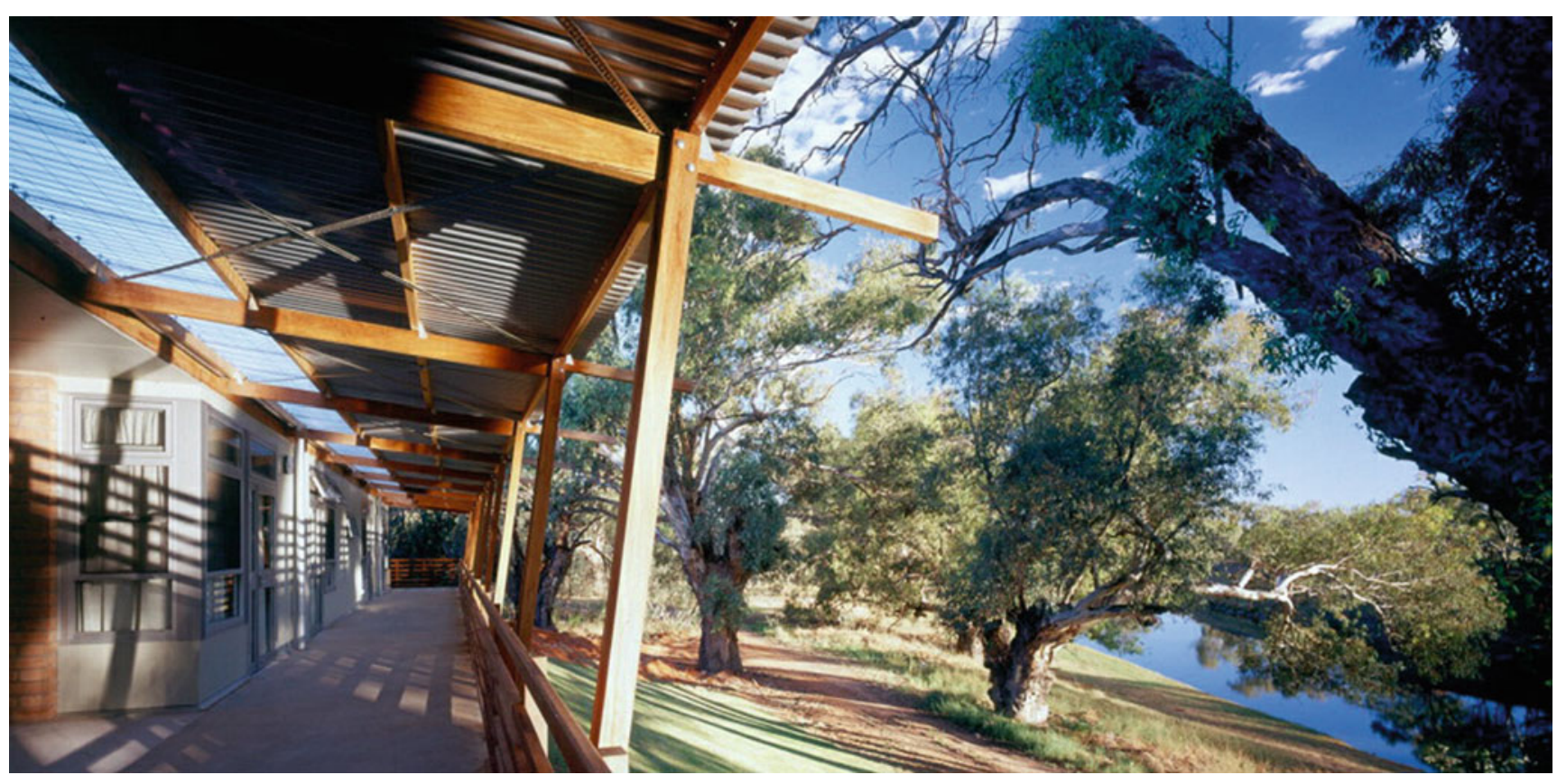

Fig. 26.6 For the Indigenous people of Australia, meaning is derived from a connection to the land and tribe. For this reason, patient rooms in Wilcannia Hospital are all on the ground floor looking out into the landscape and have a shared veranda that is big enough to

appropriately, salutogenic architecture is invariably exemplary. Some of these projects even reach beyond the accepted evidence basis for health-promoting design (generic factors like views of nature and allowances for natural daylight) and explore the realms of story-making, psychology, neuroscience and endocrinology. accommodate large numbers of visitors. Architects: Dillon Kombumerri in Merrima, an office of the NSW Government Architect (Image: Brett Boardman)

\section{Challenges for the Future}

Salutogenic principles are a practical way to integrate the dynamics of health and experience with architecture. But for people in praxis, challenges abound: in most countries the 
procurement systems are conservative-led by precedents and guidelines, and controlled by stakeholder groups who struggle to save capital, often with little regard for on-going healthcare costs. The decision-makers are usually poorly informed or simply do not believe in the capacity of aesthetics to influence health. To add to this, the pathogenic model of health is dominant in the healthcare sector, and that has enormous inertia, which will not reorient towards health promotion easily. As a result, stakeholder groups usually value functional efficiencies, traditional finishes and approaches (such as central staff stations) over what they may consider risky new inventions. Although some groups (particularly in the private sector) are beginning to understand salutogenic values, when faced with shrinking budgets, tight deadlines, constricted sites and profit-oriented project managers, even they will lack courage to go beyond landscape planting. As a result, the journey to discover that nature is just the tip of the iceberg can be difficult.

To enable the blossoming of salutogenesis in healthcare architecture, far more research-practice-based, theoretical and empirical, must be published and disseminated, and ideally through open-access journals, because architects in practice seldom have the funds to build libraries if they must pass the pay walls that protect so much knowledge today. In addition, salutogenesis should be given a place in the canon of architectural theory so it will be taught to students. The potential for salutogenic design to reduce healthcare budgets and improve health on a population level is impressive, but it must be tested and retested so the arguments for salutogenic approaches are as watertight as research for new medications.

Open Access This chapter is distributed under the terms of the Creative Commons Attribution-Noncommercial 2.5 License (http:// creativecommons.org/licenses/by-nc/2.5/) which permits any noncommercial use, distribution, and reproduction in any medium, provided the original author(s) and source are credited.

The images or other third party material in this chapter are included in the work's Creative Commons license, unless indicated otherwise in the credit line; if such material is not included in the work's Creative Commons license and the respective action is not permitted by statutory regulation, users will need to obtain permission from the license holder to duplicate, adapt or reproduce the material.

\section{References}

Antonovsky, A. (1972). Breakdown: A needed fourth step in the conceptual armamentarium of modern medicine. Social Science \& Medicine, 6(5), 537-544.

Antonovsky, A. (1979). Health, stress, and coping. San Francisco: Jossey-Bass.

Antonovsky, A. (1987). Unravelling the mystery of health. San Francisco: Jossey-Bass.
Antonovsky, A. (1996). The salutogenic model as a theory to guide health promotion. Health Promotion International, 11(1), 11.

Beauchemin, K. M., \& Hays, P. (1996). Sunny hospital rooms expedite recovery from severe and refractory depressions. Journal of Affective Disorders, 40, 49-51.

Beauchemin, K. M., \& Hays, P. (1998). Dying in the dark: Sunshine, gender and outcomes in myocardial infarction. Journal of the Royal Society of Medicine, 91, 352-354.

Bitterman, N. (2013). Psychiatric ward dayroom: Human factors and design issues. In A. Dilani (Ed.), World Health Congress. Brisbane: International Academy of Design and Health.

Calhoun, J. B. (1970). Population density and social pathology. California Medicine, 113(5), 54.

Changeux, J.-P., \& Edelstein, S. (2005). Nicotinic acetylcholine receptors: From molecular biology to cognition. New York: Odile Jacob.

City of New York. (2013). Active design: Shaping the sidewalk experience. New York: NYC.

Dancer, S. J. (2004). How do we assess hospital cleaning? A proposal for microbiological standards for surface hygiene in hospitals. Journal of Hospital Infection, 56(1), 10-15.

Dijkstra, K., Pieterse, M., \& Pruyn, A. (2006). Physical environmental stimuli that turn healthcare facilities into healing environments through psychologically mediated effects: Systematic review. Journal of Advanced Nursing, 56(2), 166-181.

Dilani, A. (2006). A new paradigm of design and health in hospital planning. World Hospitals and Health Services, 41(4), 17-21.

Dilani, A. (2008). Psychosocially supportive design: A salutogenic approach to the design of the physical environment. Design and Health Scientific Review, 1(2), 47-55.

Donne, J. (1624). Devotions upon emergent occasions and severall steps in my sicknes. London: Thomas Iones.

Floresco, S. B., Blaha, C. D., Yang, C. R., \& Phillips, A. G. (2001). Modulation of hippocampal and amygdalar-evoked activity of nucleus accumbens neurons by dopamine: Cellular mechanisms of input selection. The Journal of Neuroscience, 21(8), 2851.

Foucault, M. (1977). Discipline and punish: The birth of the prison. (A. Sheridan, Trans.) London: Allen Lane.

Frankl, V. E. (1963). Man's search for meaning: An introduction to logotherapy. New York: Pocket Books.

Golembiewski, J. (2010). Start making sense: Applying a salutogenic model to architectural design for psychiatric care. Facilities, 28 (3/4), 100-117.

Golembiewski, J. (2012a). Moving from theory to praxis on the fly: Introducing a salutogenic method to expedite mental healthcare provision. Australian Journal of Emergency Management, 27(1), $42-47$.

Golembiewski, J. (2012b). Salutogenic design: The neural basis for health promoting environments. World Health Design Scientific Review, 5(4), 62-68.

Golembiewski, J. (2013). Are diverse factors proxies for architectural influences? A case for architecture in the aetiology of schizophrenia. Cureus, 5(3), e106.

Golembiewski, J. (2014a). Mental health facility design: The case for person-centred care. Australian and New Zealand Journal of Psychiatry, 49(3), 203-206.

Golembiewski, J. (2014b). Environmental response: How architecture affects us physically and mentally (and what designers can do about it). Paper presented at Schivello Industry Meeting Conference, Schivello, Brisbane.

Golembiewski, J. (2016). The designed environment and how it affects brain morphology and mental health. Health Environments Research \& Design Journal, 9(2), 161-171. 
Howes, O. D., Williams, M., Ibrahim, K., Leung, G., Egerton, A., McGuire, P. K., et al. (2013). Midbrain dopamine function in schizophrenia and depression: A post-mortem and positron emission tomographic imaging study. Brain, 136(Pt 11), 3242-3251.

Hurst, L. (1960). The environment in chronic schizophrenia. International Journal of Social Psychiatry, 7(1), 65.

Isovich, E., Engelmann, M., Landgraf, R., \& Fuchs, E. (2001). Social isolation after a single defeat reduces striatal dopamine transporter binding in rats. European Journal of Neuroscience, 13(6), 1254.

Jackson, R., \& Sinclair, S. (2012). Designing healthy communities. San Francisco: Jossey-Bass.

Koppisetti, S., Bharat, J., Pilar Terron, M., Sandra, T., Hiroshi, T., Flores, L. J., et al. (2008). Reactive oxygen species and the hypomotility of the gall bladder as targets for the treatment of gallstones with melatonin: A review. Digestive Diseases and Sciences, 53(10), 2592-2603.

Lawton, M. P., \& Nahemow, L. (1973). Ecology and the aging process. In C. Eisdorfer \& M. Powell Lawton (Eds.), Social environment of aging (pp. 619-673). Washington, DC: American Psychological Association.

Le Hunte, B. L., \& Golembiewski, J. (2014). Stories have the power to save us: A neurological framework for the imperative to tell stories. Arts and Social Sciences Journal, 5(2), 73-77.

Mittelmark, M. B., \& Bull, T. (2013). The salutogenic model of health in health promotion research. Global Health Promotion, 20(2), $30-38$.

Parker, R. (2000). Health literacy: A challenge for American patients and their health care providers. Health Promotion International, 15 (4), 277-283.

Rao, M. L., Müller-Oerlinghausen, B., Mackert, A., Strebel, B., Stieglitz, R. D., \& Volz, H. P. (1992). Blood serotonin, serum melatonin and light therapy in healthy subjects and in patients with nonseasonal depression. Acta Psychiatrica Scandinavica, 86 (2), 127-132.
Rudd, M., Vohs, K. D., \& Aaker, J. (2012). Awe expands people's perception of time, alters decision making, and enhances wellbeing. Psychological Science, 23(10), 1130-1136.

Salmivalli, C. (2001). Feeling good about oneself, being bad to others? Remarks on self-esteem, hostility, and aggressive behavior. Aggression and Violent Behavior, 6(4), 375-393.

Searles, H. F. (1960). The non-human environment in normal development and in schizophrenia. In L. M. Newman (Ed.), Monograph Series on Schizophrenia. New York: International Universities Press.

Searles, H. F. (1966). Concerning the development of an identity. Psychoanalytic Review, 53(4), 7-30.

Sloan Devlin, A. (1992). Psychiatric ward renovation: Staff perception and patient behavior. Environment and Behavior, 24(1), 66-84.

Smith, M., Golembiewski, J., Hunyh, A., Raz, N., \& Wu, S. (2014). Al Wakrah Centre for recovery and respite. Sydney: MAAP/ Wuthering Ink.

Strümpfer, D. J. W., Gouws, J. F., \& Viviers, M. R. (1998a). Antonovsky's sense of coherence scale related to negative and positive affectivity. European Journal of Personality, 12(6), 457-480.

Stümpfer, D. J. W., Viviers, M. R., \& Gouws, J. F. (1998b). Item phrasing in Antonovsky's sense of coherence scale related to negative and positive affectivity. Personality and Individual Differences, 24(5), 669-675.

Ulrich, R. S. (1991). The effects of interior design on wellness: Theory and recent Scientific Research. Journal of Health Care Interior Design, 3, 97-109.

Vaaler, A. E., Morken, G., \& Linaker, O. M. (2005). Effects of different interior decorations in the seclusion area of a psychiatric acute ward. Nordic Journal of Psychiatry, 59(1), 19-24.

Wistow, G. (2012). Still a fine mess? Local government and the NHS 1962-2012. Journal of Integrated Care, 20(2), 101-114. 